\title{
Imiquimod-responsive basal cell carcinomas and factor XIIIa-enriched dendrocytes
}

\author{
P. Quatresooz and G. E. Piérard \\ Department of Dermatopathology, University Hospital Sart Tilman, Liège, Belgium
}

\section{Summary}

\begin{abstract}
Dermal dendrocytes (DDs) are dendritic cells that exhibit immunoreactivity for factor XIIIa, and are frequently found in conjunction with basal cell carcinomas (BCCs). Imiquimod was applied to 12 superficial BCCs every 3 days for 8 weeks. One week after completion of treatment, seven lesions appeared to have resolved, while five displayed evidence of residual BCC. Prior to initiation of treatment, the seven imiquimodresponsive BCCs were surrounded by numerous DDs, whereas the five imiquimodresistant BCCs had fewer DDs next to them at the time of entry into the study. It appears that the pretreatment density in DDs may affect the efficacy of imiquimod in eradicating skin tumours.
\end{abstract}

\section{Introduction}

The stroma of malignant neoplasms consists of a heterogeneous cell population of varied embryological origin. In the past, many of these cells were considered to be of mesenchymal origin, belonging to the connective tissue component of the organs, and generally called fibroblasts. However, the fibroblast-like cells of the skin represent different cell lineages, showing distinct phenotypes that may be explored by immunohistochemistry. Among these cells, dermal dendrocytes (DDs) are dendritic cells exhibiting immunoreactivity for factor XIIIa (FXIIa), many of which belong to the monocytemacrophage lineage. They are frequently found in conjunction with basal cell carcinomas (BCCs).

Dermal dendrocytes (DDs) are heterogeneous as regards immunophenotype, stage of maturation and function. They express different markers at specific stages of differentiation, and they alter their shape according to the influences of the extracellular matrix and neighbouring cells. DDs are involved in a series of specific functions, and interact with FXIII, which is a

Correspondence: Prof G.E. Piérard, Department of Dermatopathology, CHU Sart Tilman, B-4000 Liège, Belgium.

E-mail: Gérald.Piérard@ulg.ac.be

Accepted for publication 17 August 2003 critical transglutaminase in homeostasis of the connective tissue and in its repair processes. ${ }^{1}$

The immunomodulator imiquimod enhances the release of a series of endogenous cytokines by cells present in the skin, particularly those of the monocytemacrophage lineage. ${ }^{2,3}$ Dermal dendrocytes (DDs) might play a pivotal role in this mechanism. ${ }^{4,5}$ Imiquimod has shown efficacy in the treatment of superficial BCC. ${ }^{6}$ As with viral condylomas, ${ }^{4}$ the therapeutic success might be related to the presence of a cuff of DD abutted to the base of the neoplasm.

\section{Case report}

Twelve superficial BCC were diagnosed on the face of patients aged from 56 to 68 years. Topical applications of imiquimod were applied at 3-day intervals for 8 weeks. On clinical and dermoscopic examinations 1 week after completion of treatment, seven lesions appeared to have resolved, and five showed evidence of residual BCC. The treated skin fields were erythematous and discretely scaly. Punch biopsies were performed before treatment and 9 weeks after its initiation. Sections were prepared for immunohistochemistry using a polyclonal antibody to FXIIIa in order to identify DDs. Comparisons were made between the imiquimod-responsive and -resistant lesions. 
The seven imiquimod-responsive BCCs were surrounded by numerous DDs (median: 153/ $\mathrm{mm}^{2}$ ) before initiation of the treatment (Fig. 1a,b). Complete cure of these lesions was confirmed histologically. The site of neoplastic regression was loaded with numerous DDs (Fig. 2a,b), which were clustered in the superficial dermis, with a few scattered in the mid-epidermis, in a location where Langerhans cells are usually found.

The five imiquimod-resistant BCC had fewer DDs (median $81 / \mathrm{mm}^{2}$ ) abutted to them at entry into the study. The DD numerical density was modified little after treatment in the dermis at the site of residual BCC.

\section{Discussion}

Host-tumour interactions clearly influence the ultimate behaviour and prognosis of malignancies. Besides the crucial role of the immune response, the tumour stroma with various cytokines and enzymes is involved in the control of tumour growth, regression and metastatic progression. ${ }^{7,8}$ The mode of action of stromal cells remains controversial and enigmatic. Indeed, several lines of evidence suggest that the stroma may display both stimulatory and restrictive effects upon tumour progression. $^{9-12}$ The presence of DDs in malignant cutaneous neoplasms has been of increasing interest during the past decade. ${ }^{12-15}$ Given the histogenetic diversity of the cell types expressing FXIIIa, ranging from bone-marrow to mesenchyme-derived cells, several specific cellular functions may be involved in cutaneous cancers. In particular, they may produce a variety of cytokines, such as tumour necrosis factor- $\alpha,{ }^{16}$ which may operate through a paracrine mechanism upon other stromal cells and the malignant lineage. ${ }^{7-9}$ Similarly to the wound-healing process, the peritumoural stroma is probably enriched in cytokines, growth factors, metalloproteinases and their inhibitors. ${ }^{17}$ Variations in the resulting molecular interplay may result in effects as distinct as tumoral progression or regression.

Extravascular fibrin deposits are frequently present within and around neoplasms. They are involved in various aspect of tumour growth. Some tumour-associated macrophages belong to the DD population. They are present in areas of fibrin deposition in some neoplasms. This situation strongly suggests that FXIIIa is involved in the stabilization of the intratumural fibrin network that facilitates tumour-matrix relationships and tumour angiogenesis. FXIIIa-positive DDs prevail over all other cell types at the site of intratumoral fibrin deposits in different malignancies, and are strongly attached to the fibrin network. FXIII probably plays a significant role in fibrin stabilization and consequently has an effect on tumour progression.

The present observation is in line with previous findings, ${ }^{3-5}$ suggesting that the pretreatment density in dermal DDs may affect the efficacy of imiquimod in eradicating skin tumours. It is therefore suggested that in cases of imiquimod treatment failure, combination with another agent in order to boost DDs might be beneficial. As such, topical retinoids, $\alpha$-hydroxyacids and $\beta$-lipohydroxyacid are compounds that could be useful, although they may increase the risk of more severe local skin reactions.
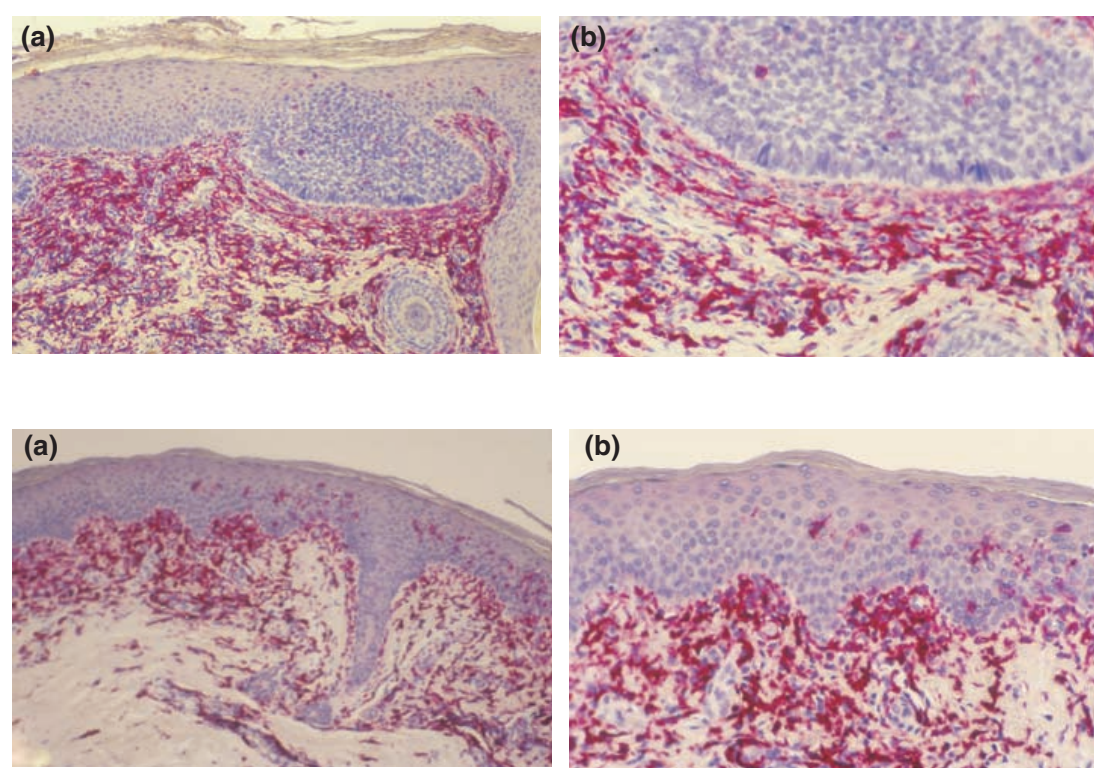

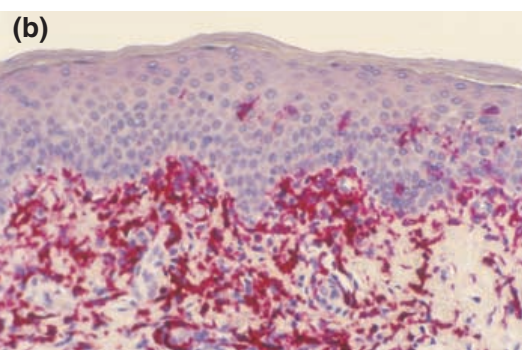

Figure 1 Superficial basal cell carcinoma before imiquimod treatment. The neoplasm is underlined by a dense population of factor XIIIa-positive dendrocytes. Original magnification: $(a) \times 80$, (b) $\times 160$.

Figure 2 After 8 weeks of imiquimod treatment, the basal cell carcinoma has completely regressed. The density in factor XIIIa-positive dendrocytes is high in the superficial dermis. Similar cells are scattered in the epidermis. Original magnification: (a) $\times 80$, (b) $\times 160$. 


\section{References}

1 Griffin TD, Murphy GF, Sueki H et al. Increased factor XIIIa transglutaminase expression in dermal dendrocytes after treatment with $\alpha$-hydroxyacids: potential physiologic significance. J Am Acad Dermatol 1996; 34: 196203.

2 Dockrell DH, Kinghorn GR. Imiquimod and resiquimod as novel immunomodulators. J Antimicrob Chemother 2001; 48: 751-5.

3 Hermanns-Lê T, Nikkels AF, Uhoda I, Petit L, Piérard GE. Imiquimod $\left(\right.$ Aldara $\left.^{\circledR}\right)$ : an immune response modifier for the skin. Rev Med Liege 2002; 57: 116-8.

4 Arrese JE, Paquet P, Claessens N, Piérard-Franchimont C, Piérard GE. Dermal dendritic cells in anogenital warty lesions unresponsive to an immune-response modifier. J Cutan Pathol 2001; 28: 131-4.

5 Hermanns-Lê T, Paquet P, Nikkels AF, Piérardfranchimont C, Piérard GE. Prolonged imiquimod treatment and graft-versus-host reaction: histological mimicry in the pattern of monocyte-macrophage-dendrocyte lineage skin infiltration. Dermatology 2003; 206: 361-5.

6 Beutner KR, Geisse JK, Helman D, Fox TL, Ginkel A, Owens ML. Therapeutic response of basal cell carcinoma to the immune response modifier imiquimod 5\% cream. J Am Acad Dermatol 1999; 41: 1002-7.

7 Graves D, Valente A. Monocyte chemoattractants produced by malignant cells. J Pathol 1990; 161: 187-8.

8 Zipori D. Stromal cells in tumor growth and regression. Cancer J 1990; 3: 164-9.

9 Kratochwil K. The stroma and the control of cell growth. J Pathol 1986; 149: 23-4.
10 Bugelski PJ, Corwin SP, North SM, Kirsch RL, Nicolson GL, Poste G. Macrophage content of spontaneous metastases at different stages of growth. Cancer Res 1987; 47: 4141-5.

11 Zipori D. Stromal cells in tumor growth and regression. Cancer 1990; 3: 164-9.

12 Piérard-Franchimont C, Arrese JE, Nikkels AF, Al-saleh W, Delvenne P, Pierard GE. Factor XIIIa-positive dermal dendrocytes and proliferative activity of cutaneous cancers. Virchows Arch 1996; 429: 43-8.

13 Arrese JE, Piérard GE. Factor XIIIa-positive dendrocytes and the dermal microvascular unit. Dermatologica 1990; 180: $51-3$.

14 Al-Saleh W, Delvenne P, Arrese JE, Nikkels AF, Piérard GE, Boniver J. Inverse modulation of intraepithelial Langerhans' cells and stromal macrophage/dencrocyte populations in human papillomavirus-associated squamous intraepithelial lesions of the cervix. Virchows Arch 1995; 427: 41-8.

15 Nestle FO, Nickoloff BJ. A fresh morphological and functional look at dermal dendritic cells. J Cutan Pathol 1995; 22: 385-93.

16 Nickoloff BJ, Griffiths CEM. Lymphocyte trafficking in psoriasis: a new perspective emphasizing the dermal dendrocyte with active dermal recruitment mediated via endothelial cells followed by intra-epidermal T-cell activation. J Invest Dermatol 1990; 95: 35s-37s.

17 Quatresooz P, Henry F, Paquet P, Piérard-Franchimont C, Harding K, Piérard GE. Deciphering the impaired cytokine cascades in chronic leg ulcers. Int J Molec Med 2003; 11 : 411-8. 